PAPER • OPEN ACCESS

Characterization of optimized activated carbon production from soyabeans pod

To cite this article: O O Olawale et al 2020 IOP Conf. Ser.: Earth Environ. Sci. 445012054

View the article online for updates and enhancements. 


\title{
Characterization of optimized activated carbon production from soyabeans pod
}

\author{
O O Olawale ${ }^{1}$, K S Obayomi ${ }^{1 *}$ and O D Raphael ${ }^{2}$ \\ ${ }^{1}$ Department of Chemical Engineering, College of Engineering, Landmark University \\ Omu-Aran Kwara State, Nigeria \\ ${ }^{2}$ Department of Agricultural and Biosystems Engineering, College of Engineering, \\ Landmark University Omu-Aran Kwara State, Nigeria \\ *Corresponding author email: obayomi.kehinde@1mu.edu.ng
}

\begin{abstract}
The experimental design was targeted at characterizing the optimized production of activated carbon from soyabeans pod through the means of phosphoric acid as an activating agent. The three parameters considered for the optimization process was impregnation ratio $(0.5-1.5 \mathrm{M})$, activation time $(60-120 \mathrm{~min})$ and activation temperature $\left(200-600{ }^{\circ} \mathrm{C}\right)$. The central composite strategy which is a feature of the RSM was utilized to achieve the optimal preparation conditions. The optimum conditions obtained for the good percentage of yield response was $1.06 \mathrm{M}, 305.34{ }^{\circ} \mathrm{C}$ and $89.95 \mathrm{~min}$. The ANOVA result gathered revealed that acid concentration has the most substantial impact on the response yield shadowed by activation temperature and activation time, respectively. Brunauer Emmett Teller (BET), Scanning Electron Microscope (SEM) and Fourier Transform Infrared Spectroscopy (FTIR) analysis were carried out on the samples. The raw and produced activated carbon from soyabeans pod BET surface region was 228.2 and $709 \mathrm{~m}^{2} / \mathrm{g}$, respectively.
\end{abstract}

\section{Introduction}

Activated Carbon (AC) has become an essential and widely utilized absorbent. AC is an insipid solid, a microcrystal and non-graphitisable mode of dense carbonaceous material with absorptive construction. It is viewed as a special and adaptable adsorbent owing to its extended surface region, microporous construction, adsorption capacity, and surface reactivity [1,2]. Given the ample nature of agrarian byproducts and its availability, this makes them a major source of raw materials for the preparation of AC. Nevertheless, this has forged ahead in developing investigative interest for the utilization of substitute waste materials from industry and agriculture for AC preparation. By virtue of the relevance and utilization of activated carbon in mostly, if not all the areas of life, it is impossible to lay too much emphasis on its importance. This is because it furthers the quest for a means for its production beyond the recognized techniques. Based on this, studies and new developments on the utilization of numerous agrarian byproducts to produce activated carbon are carried out [3-6]. Following the consistency of the trend for development with virtually every habitation of man aimed at urbanization, there is a high propensity that the demand for activated carbon would also sour. As a result, it is essential for individuals, enterprises, and 
nations to be ready to supply this demand. There are environmental and economic consequences aimed at the preparation of activated carbon from agrarian by-products since it changes unacceptably small-valued agrarian waste to relevant and highly sought after adsorbent [7]. AC can be created from natural material and synthetic carbonaceous solid precursor [8]. The nature of starting material otherwise referred to as the precursor, acts as a vital influencing factor on the value, properties and features of the subsequent activated carbon [9]. Additionally, certain variables including, impregnation conditions, activation time, and carbonization activation temperature will also influence the attributes of the subsequent activated carbon $[10,11]$. To regulate the diverse factors which impact and interfere in the production, the emperical approach have been implemented, so as to optimize experimental conditions [12]. The two basic - yet diverse processes for activated carbon preparation include; physical and chemical treatment. The two treatments are responsible for the changing shapes and sizes. AC production by physical activation requires great activation temperatures $\left(800-1000{ }^{\circ} \mathrm{C}\right)$ that involve heightened power consumption and a small yield of carbon [13]. Contrastively, in the chemical activation, the carbonization activation temperature ranges from 400 to $600{ }^{\circ} \mathrm{C}$. Furthermore, in chemical treatment, precursors are often permeated by an activating reagent and accompanied via reheating method. The chemical activating agents generally used by researchers for AC production among others are $\mathrm{NaOH}, \mathrm{KOH}, \mathrm{K}_{2} \mathrm{CO}_{3}, \mathrm{HNO}_{3}$ and $\mathrm{ZnCl}_{2}$. The chemical technique need lesser activation temperatures, generates greater yield and create completely-developed microporosities. Conditional to the state of the production procedure, the normal surface regions for activated carbon range from 500 to $1400 \mathrm{~m}^{2} / \mathrm{g}$, though values as great as $2500 \mathrm{~m}^{2} / \mathrm{g}$ have been recounted [13]. There is a potential economic and environmental impact of the manufacture of activated carbon from agrarian by-products. To begin with, it converts inferior agrarian waste to invaluable adsorbents. Then, activated carbons are more progressively utilized in water to get rid of organic chemicals and metals of economic and environmental concern. Lastly, the import of activated carbon will be lessened thereby snowballing our economy as a nation [2]. Consequently, the purpose of this study is to optimize and illustrate the production of activated carbon from soyabeans pod activated with phosphoric acid.

\section{Materials and method}

\subsection{Materials}

The phosphoric acid implemented for this experimental design was provided by Aldrich and Sigma Chemicals Malaysia, and was additionally utilized devoid of any purification. Also, the Soyabeans pod utilized were obtained from a soyabeans plantation in Landmark University Farm of Omu-Aran, Kwara State. To remove foreign bodies the soyabeans pods were washed desiccated for 4 days and then left to dry in a furnace at $120^{\circ} \mathrm{C}$ for 4 hours.

\subsection{Activated carbon preparation}

The three parameter under study for soyabeans pod $\mathrm{AC}$ development with $\mathrm{H}_{3} \mathrm{PO}_{4}$ acid as an activating agent are: impregnation ration $(0.5-1.5 \mathrm{M})$; activation temperature $\left(200-600{ }^{\circ} \mathrm{C}\right)$; and activation time of activation (60-120 min). The desiccated soyabeans pod was crumpled and sieve to a particle's size of 200-500 $\mu \mathrm{m}$. Afterwards, it was measured and encumbered in a stainless steel crucible into the oven at a heating rate of $5^{\circ} \mathrm{C} / \mathrm{min}$ and $150 \mathrm{~cm}^{3} / \mathrm{min}$ under purified atmospheric nitrogen $(98.99 \%)$ for carbonization at an activation temperature of $500{ }^{\circ} \mathrm{C}$ for $1 \mathrm{~h}$. The prepared soyabeans pod char after carbonization was impregnated with phosphoric acid (activating agent) with impregnation ratio of the activating agent to the precursor being retained at $5 \mathrm{~g} / 100 \mathrm{~mL}$ (char/acid) in a $250 \mathrm{~mL}$ beaker as stipulated by the DOE in Table 2. The sample was left overnight in an oven at $120^{\circ} \mathrm{C}$ after being shaken for $2 \mathrm{~h}$ at $140 \mathrm{rpm}$. At a desired activation temperature and activation time as decidedby the Design of Experiment (DOE) in Table 2, the impregnated char were then activated thermally in an oven. The sample was eroded with distilled water in other to attain neutral $\mathrm{pH}$ (6.9-7)after chemical activation. Afterwards, it was desiccated in a furnace at $108{ }^{\circ} \mathrm{C}$ for $4 \mathrm{~h}$, reduced to particles size of $125 \mu \mathrm{m}$ and stowed in an impermeable vessel for additional use. 


\subsection{Design of experiment (DOE)}

In furtherance of the study of the effect of both individual and double interaction of the three factors studied towards the percentage yield response of the produced activated carbon,Central composite design (CCD), an aspect of the response surface methodology (RSM) among other emperical designs, was used. The Central Composite Design is specifically described by three operations including: 6 axial runs $\left(2^{\mathrm{n}}\right), 8$ factorial runs $(2 \mathrm{n})$ and 6 center runs which equate to 20 experimental runs.

Total number of experiments $=2^{\mathrm{n}}+2 \mathrm{n}+\mathrm{n}_{\mathrm{c}}$

Where $\mathrm{n}$ represents the figure of the factor and $\mathrm{n}_{\mathrm{c}}$ is the center points figure (six replicates). The coded points and their equivalent values are depicted in Table 1.

Table1. Central composite design independent variables and coded levels

\begin{tabular}{lllcc}
\hline Variables & Unit & \multicolumn{3}{c}{ Coded levels } \\
\cline { 3 - 5 } & & $\mathbf{- 1}$ & $\mathbf{0}$ & $\mathbf{1}$ \\
Impregnation ratio & - & 0.5 & 1.0 & 1.5 \\
Activation temperature & ${ }^{\circ} \mathrm{C}$ & 200 & 400 & 600 \\
Activation time & Min & 60 & 90 & 120 \\
\hline
\end{tabular}

The optimal predictor model quadratic equation as shown below was used to estimate the optimal variables situations for the percentage yield response on the produced activated carbon from soyabeans pod:

$\mathrm{Y}=\mathrm{b}_{\mathrm{o}}+\sum_{i=1}^{n} b_{i} x_{i}+\left(\sum_{i=1}^{n} b_{i} x_{i}\right)^{2}+\sum_{i=1}^{n-1} \sum_{j=i+1}^{n} b_{i j} x_{i} x_{j}$

Given that $\mathrm{Y}$ is the response predictor response, $b_{o}$ is the coefficients constant, $b_{i i}$ is the quadratic coefficients, $b_{\mathrm{ij}}$ is the coefficients interaction and $\mathrm{x}_{\mathrm{i}}, \mathrm{x}_{\mathrm{j}}$ are the coded variables values deliberated. Using Design Expert software (statistical) version 11.0.0 (STAT-EASE Inc., Minneapolis, USA), the regression analysis appropriate for the equation of the yield (response) established, as well as the estimation of the statistical importance of the equation attained with the help of the experimental data, were evaluated. The nature of dependability of experimental analysis undertaken was calculated by the detected response values variability conveyed by $\mathrm{R}^{2}$ coefficient determined, the $\mathrm{P}$-values probability ( $95 \%$ confidence level) and test Fisher's values. The yield percentage of the produced soyabeans pod activated carbon was calculated as:

Yield $(\%)=\frac{\text { dried weight of the produced activated acrbon }(g)}{\text { dried weight of the used precursor }(g)} \times 100$

Table 2. RSM experimental matrix for the development of soyabeans Activated carbon

\begin{tabular}{llllll}
\hline Runs & $\begin{array}{l}\text { Impregnation } \\
\text { ratio (A) }\end{array}$ & $\begin{array}{l}\text { Activation temperature } \\
(\mathrm{B})\left({ }^{\circ} \mathrm{C}\right)\end{array}$ & $\begin{array}{l}\text { Activation } \\
(\mathrm{C})(\mathrm{min})\end{array}$ & $\begin{array}{l}\text { Experimental } \\
\text { yield }(\%)\end{array}$ & $\begin{array}{l}\text { Predicted yield } \\
(\%)\end{array}$ \\
\hline 1 & -1 & -1 & -1 & 40.22 & 41.00 \\
2 & +1 & -1 & -1 & 26.67 & 26.41 \\
3 & -1 & +1 & -1 & 39.44 & 38.74 \\
4 & +1 & +1 & -1 & 18.11 & 18.48 \\
5 & -1 & -1 & +1 & 39.01 & 38.39 \\
6 & +1 & -1 & +1 & 28.45 & 28.91 \\
7 & -1 & +1 & +1 & 39.67 & 39.68 \\
8 & +1 & +1 & +1 & 25.56 & 24.53 \\
9 & -1 & 0 & 0 & 42.56 & 43.10 \\
10 & +1 & 0 & 0 & 27.77 & 28.23 \\
\hline
\end{tabular}




\begin{tabular}{rrrrrr}
\hline 11 & -1 & -1 & 0 & 38.46 & 38.11 \\
12 & 0 & +1 & 0 & 33.44 & 34.79 \\
13 & 0 & 0 & -1 & 32.87 & 32.68 \\
14 & 0 & 0 & +1 & 33.22 & 34.40 \\
15 & 0 & 0 & 0 & 36.65 & 36.82 \\
16 & 0 & 0 & 0 & 36.76 & 36.82 \\
17 & 0 & 0 & 0 & 36.95 & 36.82 \\
18 & 0 & 0 & 0 & 38.76 & 36.82 \\
19 & 0 & 0 & 0 & 36.89 & 36.82 \\
20 & 0 & 0 & 0 & 36.87 & 36.82 \\
\hline
\end{tabular}

\subsection{Proximate analysis}

In accordance with ASTM D 121 methods in determining the volatile content, moisture content, ash content and fixed, the proximate analysis on the precursor was performed.

2.4.1Moisture content. $5 \mathrm{~g}$ of the dried-raw and activated carbon samples were weighed and moved into a crucible. In accordance with the [14] method, the crucibles were positioned in a furnace and desiccated at $108^{\circ} \mathrm{C}$ to continual weight for $5 \mathrm{~h}$. The moisture content percentage was calculated using:

$\%$ Moisture content $=\frac{\text { loss in weight on drying }(g)}{\text { initial sample weight before drying }(g)} \times 100$

2.4. 2 Ash content and volatile matter. A crucible was firstly subjected to heat in a muffler furnace to about $400{ }^{\circ} \mathrm{C}$, left to cool off within a desiccator and weighed. $5 \mathrm{~g}$ of raw and activated carbon from soyabeans pod were moved to the crucibles and weighed again. The crucibles housing the samples were further transferred to a muffler oven at a temperature of $400^{\circ} \mathrm{C}$. It was then detached from the furnace and cooled in a desiccator to about $25^{\circ} \mathrm{C}$ and reweighed once more. The following equations represent the ash content and volatile matter of the raw activated carbon out of soyabeans pod:

$\%$ Ash content $=\frac{\text { ash weight }(g)}{\text { oven dry weight }} \times 100$

$\%$ Volatile content $=\frac{\text { weight of volatile material }}{\text { oven dry weight }} \times 100$

2.4.3Fixed carbon. By deducting the cumulativeness of the ash content, moisture content and volatile matter from 100, the fixed carbon for the raw and activated carbon from soyabeans were evaluated.

Fixed carbon $=100-($ ash content + volatile content + moisture content $)$

2.5 Representation of the raw and activated carbon prepared from soyabeans pod

Brunauer-Emmett-Teller (BET) surface region and permeability of the raw and activated carbon produce from the samples were decided through Micrometrics (ASAP 2000, US) nitrogen adsorption-desorption technique. The morphological surfaces of char and activated carbon produced from soyabeans pod were captured by means ofa scanning electron microscopy (SEM) (Model Leo Supra 50VP Field Emission, UK). While the surface chemistry raw plus activated carbon were determined with Fourier transform infrared (FTIR) spectroscope (FTIR-2000, PerkinElmer).

\section{Results and discussion}

\subsection{Proximate and elemental analysis}

The analysis (proximate and elemental) on the raw-activated carbon formed from soyabeans pod is given in Table 3-4. The moisture content of both the raw and activated carbon were 3.21 and $4.67 \%$, ash content of 8.46 and $6.90 \%$ and fixed carbon of 35.68 and $53.65 \%$. Perhaps, the organic matters present in the 
precursor are responsible for the increased volatile content $(52.65 \%)$ of the raw soyabeans pod before carbonization. The high-fixed carbon with regards to the activated carbon is possibly the outcome of the acid activation on the produced char. The elemental analysis reveals that carbon is present in major quantity whereas the other elements are present in a noticeable amount.

Table 3. Proximate analysis on raw and prepared soyabeans pod activated carbon,

\begin{tabular}{lll}
\hline Property & Raw material (\%) & Prepared activated carbon (\%) \\
\hline Moisture content & 3.21 & 4.67 \\
Ash content & 8.46 & 6.90 \\
Volatile content & 52.65 & 34.78 \\
Fixed carbon & 35.68 & 53.65 \\
\hline
\end{tabular}

Table 4. Elemental analysis on raw and prepared soyabeans pod activated carbon.

\begin{tabular}{lll}
\hline Element & Raw material (\%) & Prepared activated carbon (\%) \\
\hline Carbon & 60.25 & 71.48 \\
Oxygen & 15.50 & 9.27 \\
Hydrogen & 15.65 & 15.55 \\
Sulphur & 8.60 & 3.7 \\
\hline
\end{tabular}

\subsection{Development of Regression equation model development}

The software for the production of soyabeans pod activated carbon established the quadratic model as proposed by the CCD an aspect of the RSM. In table 2, as shown on the experimental design matrix, the activated carbon from soyabeans pod response (yield) gotten was in the range of $18.11-42.56 \%$. The six duplicated midpoints (run 15-20) were carried out to check data reproducibility as well as to decide the experimental error. The high relative characteristics of these values attained for the three variables under analysis suggest a qualitative synchronization amid the predicted values and the experimental values. The coded equation on behalf of the yield percentage soyabeans pod activated carbon is:

$$
\begin{aligned}
& \text { Yield }=+36.82-7.43 \mathrm{~A}-1.66 \mathrm{~B}+0.8600 \mathrm{C}-1.42 \mathrm{BC}+1.28 \mathrm{AC}+0.8888 \mathrm{BC}-1.15 \mathrm{~A}^{2}-0.3695 \mathrm{~B}^{2} \\
& -3.27 \mathrm{C}^{2}
\end{aligned}
$$

Centered on the maximum order polynomials, the model was chosen according to sequential model sum of squares, where the supplementary terms were important and the models were not aliased $[15,16]$. The fitness of the developed model was evaluated using the standard deviation and correlation coefficient. There is a higher possibility for the model to predict the response when the $R^{2}$ value is closer to the unity and also based on the smaller the standard deviation [17]. The quadratic model has a moderately lesser standard deviation of 1.03 and moderately higher $R^{2}$ value of 0.9973 with anticipated $R^{2}(0.9776)$ in practical synchronization with adjusted $R^{2}(0.9921)$ as depicted inTable 5 . Through the result it was also detected that the quadratic model for yield responsewas not aliased, suggesting that the quadratic model can be utilized for the assessment of the connection amid yield response in addition to the interrelating variables, revealing a good relationshipamid the predicted and the experimental value. The $R^{2}$ value of 0.9973 implied that 99.73 $\%$ of the percentage yield variation could be credited to thethree factors ( $A$-acid activation; $B$-activation temperature; $C$-activation time) considered. Consequently,the quadratic model was carefully selected as proposed by thesoftware.

Table 5. Regression statistics for the production of activated carbon from soyabeans pod

\begin{tabular}{llllll}
\hline Source & $\begin{array}{l}\text { Standard } \\
\text { deviation }\end{array}$ & $\mathrm{R}^{2}$ & Adjusted $\mathrm{R}^{2}$ & Predicted $\mathrm{R}^{2}$ & Comment \\
\hline Linear & 2.95 & 0.8081 & 0.7721 & 0.6449 & \\
\hline
\end{tabular}




\begin{tabular}{llllll}
\hline 2FI & 2.83 & 0.8568 & 0.7907 & 0.0995 & \\
Quadratic & $\mathbf{1 . 0 3}$ & $\mathbf{0 . 9 9 7 3}$ & $\mathbf{0 . 9 9 2 1}$ & $\mathbf{0 . 9 7 7 6}$ & Suggested \\
Cubic & 0.9520 & 0.9925 & 0.9763 & -2.8208 & Aliased \\
\hline
\end{tabular}

\subsection{Analysis of variance (ANOVA)}

The ANOVA was further implemented in order to accentuate the competence of the model and its connotation. The ANOVA mean square for the surface response quadratic model was attained through the division of the totality of the square of every of the variation sources, the model and the error variance by each degrees of independence as presented in table 6 . The Model F-value of 74.66 suggeststhat the model is important holding only a $0.01 \%$ probability that its enormousness could occur on the basis of induced variation under typical operating conditions throughirrepressible factor (noise).Expectedly, insignificant absence of fit was attained with absence of fit $\mathrm{F}$-value of 2.35 suggesting its insignificance in relation to the pure error and the possibilities that $18.47 \%$ of its value also ensued based on noise [18-20]. P-values less than 0.0500 point toward the significance of model terms as well as largest $\mathrm{F}$-value indicating that the model term have the greatest significant consequence on the response. In this scenario $\mathrm{A}, \mathrm{B}, \mathrm{C}, \mathrm{AB}, \mathrm{AC}$, $\mathrm{BC}, \mathrm{C}^{2}$ are the important model terms while $\mathrm{A}^{2}$ and $\mathrm{B}^{2}$ are the unimportant model terms. The model term withholding the greatest significant effect on the response is Awith $F$-value of 518.34 and the effect is respectively as follows: $\mathrm{A}>\mathrm{C}^{2}>\mathrm{B}>A B>\mathrm{AC}>\mathrm{C}>\mathrm{B} C$.

Table 6. ANOVA for response surface quadratic model percentage yield for prepared soyabeans pod activated carbon.

\begin{tabular}{lllllll}
\hline Source & $\begin{array}{l}\text { Sum of } \\
\text { square }\end{array}$ & $\mathrm{df}$ & $\begin{array}{l}\text { Mean } \\
\text { square }\end{array}$ & F-value & P-value & Comment \\
\hline Model & 716.42 & 9 & 79.60 & 74.66 & $<0.0001$ & Significant \\
A-Impregnation ratio & 552.64 & 1 & 552.64 & 518.34 & $<0.0001$ & Significant \\
B-Activation temperature & 27.52 & 1 & 27.52 & 25.81 & 0.0005 & Significant \\
C-Activation time & 7.40 & 1 & 7.40 & 6.94 & 0.0250 & Significant \\
AB & 16.05 & 1 & 16.05 & 15.05 & 0.0031 & Significant \\
AC & 13.03 & 1 & 13.03 & 12.22 & 0.0058 & Significant \\
BC & 6.32 & 1 & 6.32 & 5.93 & 0.0352 & Significant \\
$\mathrm{A}^{2}$ & 3.67 & 1 & 3.67 & 3.44 & 0.0934 & Not significant \\
$\mathrm{B}^{2}$ & 0.3756 & 1 & 0.3756 & 0.3522 & 0.5660 & Not significant \\
$\mathrm{C}^{2}$ & 29.49 & 1 & 29.49 & 27.66 & 0.0004 & Significant \\
Residual & 10.66 & 10 & 1.07 & & & \\
Lack of fit & 7.48 & 5 & 1.50 & 2.35 & 0.1847 & Not significant \\
\hline
\end{tabular}

The actual against predicted values plot of yield response presented in Figures 1, shows a highly negligibledeviation from the diagonal point, signifying that themodel can be implemented to effectively exemplify the interface of the three parameters under study. 


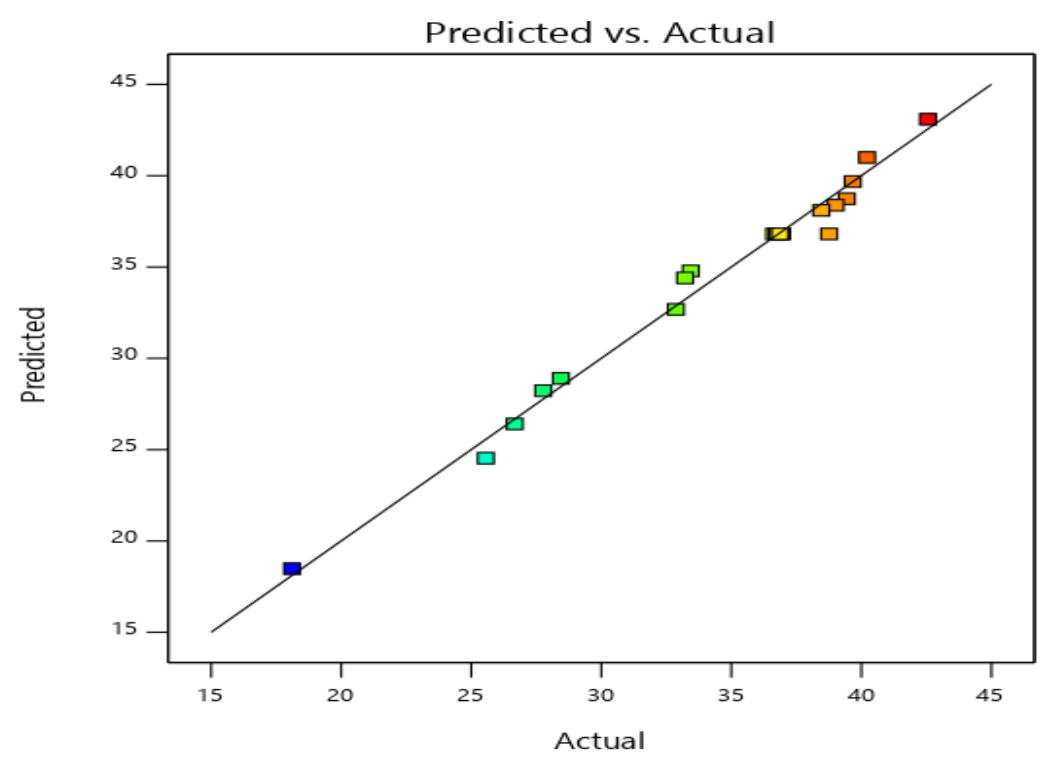

Figure 1. Actual against predicted value plot on soyabeans pod activated carbon percentage yield.

\subsection{Three dimensional plots}

Figure 2a displays that acid concentration in addition to activation temperature has remarkable joint consequences on percentage yield with impregnation ratio showing the highest consequence, although activation temperature demonstrates practical consequences too. The joint outcome was detected to be more at greater values of the dual factors. Also, it was noticed that evena slight reduction of the factors heightens the yield percentage. Also, Figure $2 \mathrm{~b}$ shows the joint consequences of activation time and impregnation ratio on the prepared soyabeans pod activated carbon percentage yield. It was seen from the result obtained that both factors have remarkably joint outcomes on the percentage response. The joint outcome was detected to be more at greater values of the dual factors. The figure shows that the joint outcome is more or less entirely as a product of the singular effect of impregnation ratio with activation time maintaining lesser effect. It was noticed as well that yield percentage is pointedly amplified with decrease in impregnation ratio while rise in activation time leads to comparatively rise in yield. Furthermore, figure $2 \mathrm{c}$ demonstrates that activation time and activation temperature has fairly small joint consequence on yield. It was detected that the result of activation temperature is fairly greater than that of activation time and an upsurge in any of both features increases the percentage yield. Additionally, it was detected that activation temperature significantly controls the joint consequence of both factors with activation time holding slight effect. 
a.

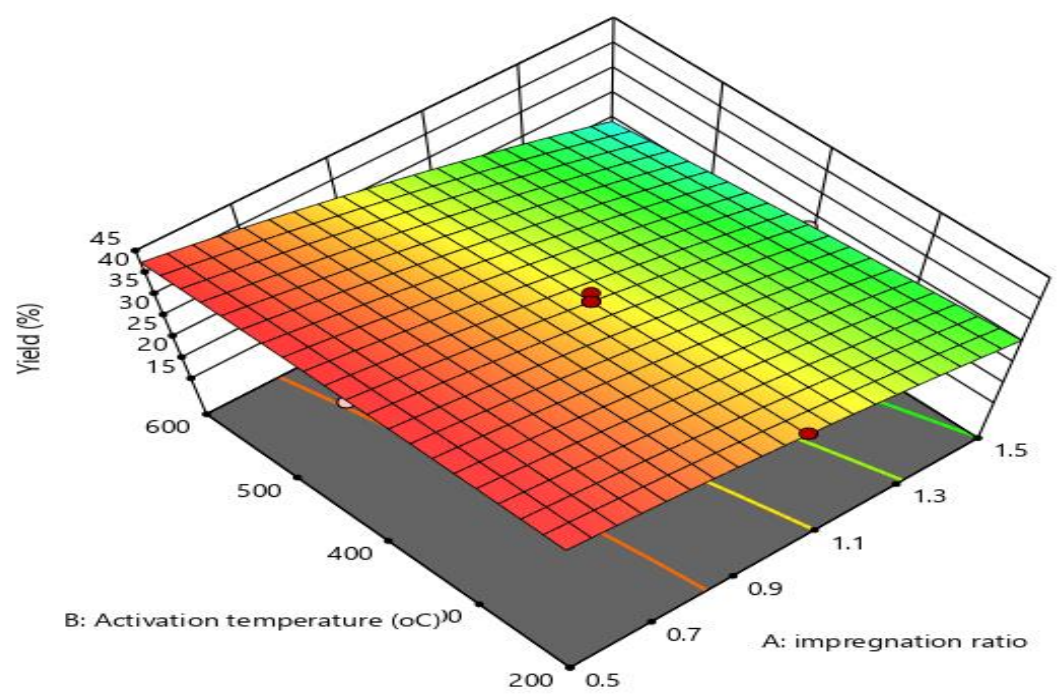

b.
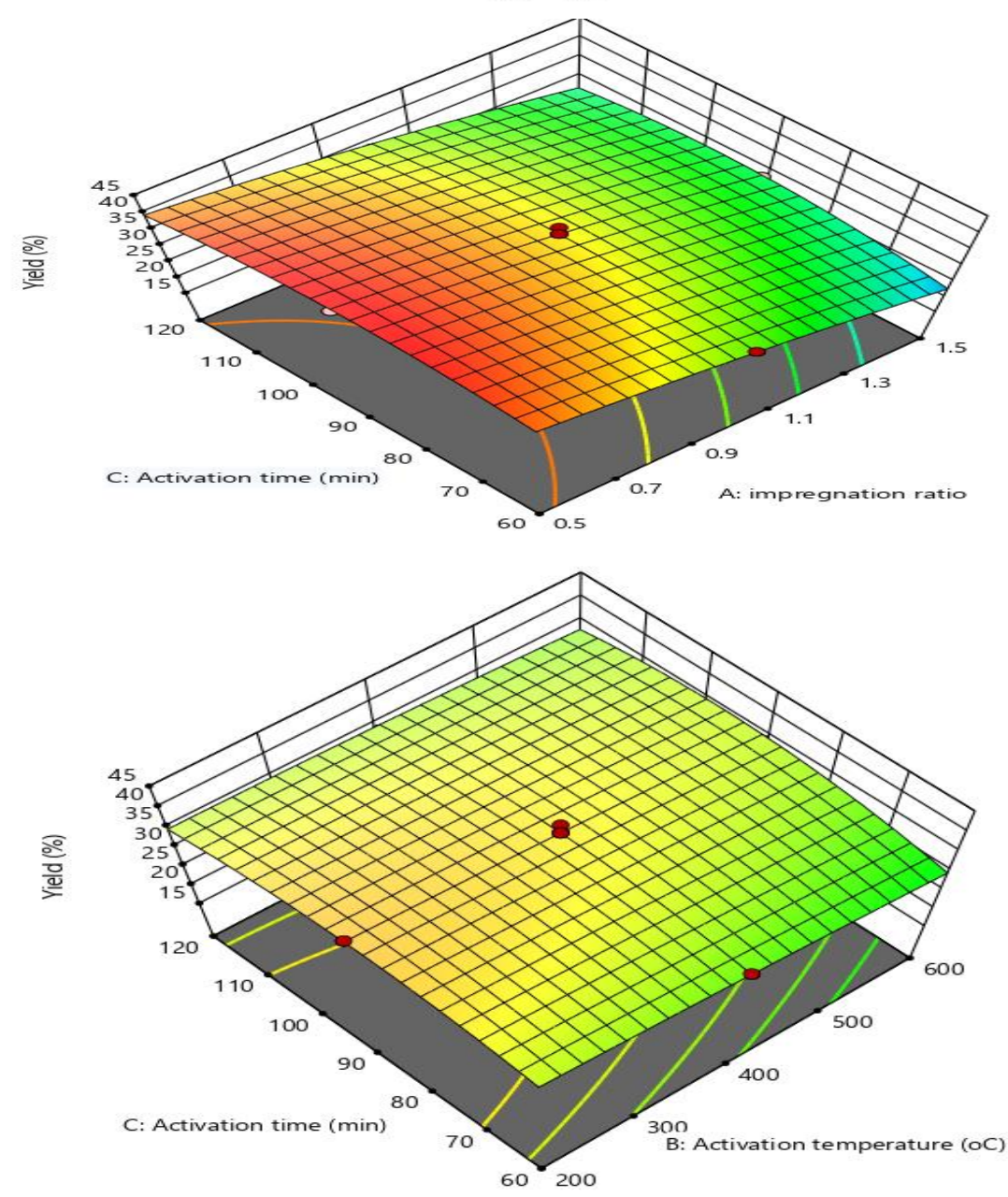

c.

Figure 2. 3- dimensional response surface plots for soyabeans pod activated carbon percentage yield (a) impregnation ratio and activation temperature at constant activation time $=90$ minutes, (b) impregnation ratio and activation time at constant activation temperature $=400{ }^{\circ} \mathrm{C}$ (c) activation temperature and activation time at constant impregnation ratio 1.0. 


\subsection{Process optimization}

The condition variables under study were the variables considered to optimize the percentage yield for soyabeans pod activated carbon production. The design expert software was implemented to ease jointly encountered difficulties as soon as more than one variable are used. The design expert software was applied for the optimization of the percentage yield response with similar circumstances of the variables considered with minimal inaccuracy. An assenting experiment was conducted on the response projected as attained from the application software to test the association and its appropriateness. The outcomes for the percentage response were $36.02 \%$ with error of $1.64 \%$ which was obtained from the result predicted of $36.62 \%$. Therefore, the peak operating circumstances for activated carbon from soyabeans pod production is as follows: $1.06 \mathrm{M}, 305.34{ }^{\circ} \mathrm{C}$, and $89.95 \mathrm{~min}$ as depicted in table 7 .

$\underline{\text { Table 7.Validation of model for prepared soyabeans activated carbon }}$

\begin{tabular}{llllll}
\hline $\mathrm{A}$ & $\mathrm{B}\left({ }^{\circ} \mathrm{C}\right)$ & $\mathrm{C}(\mathrm{min})$ & Predicted value & $\begin{array}{l}\text { Experimental } \\
\text { value }\end{array}$ & Error $(\%)$ \\
\hline 1.06 & 305.34 & 89.95 & 36.62 & 36.02 & 1.64 \\
\hline
\end{tabular}

\subsection{BET, SEM and FTIR analysis}

The multipoint Brunauer-Emmett-Teller exterior regions with raw and activated carbon from soyabeans pod were 228.2 and $709 \mathrm{~m}^{2} / \mathrm{g}$. The total pore volume of the raw soyabeans pod amounts to $0.0204 \mathrm{~cm}^{3} / \mathrm{g}$ with a cumulative pore size of $6.538 \mathrm{~nm}$. Contrastively, the activated carbon has cumulative pore volume of $0.0872 \mathrm{~cm}^{3} / \mathrm{g}$ and pore size of $5.839 \mathrm{~nm}$. The exterior region and pore volume development may possibly be ascribed to the acid activation with phosphoric acid after carbonization. Figure 3 aptly presents the raw and activated carbon soyabeans pod SEM images. The raw soyabeans pod revealed its dense and compacted characteristics. This could be attributed to numerous volatile components in form of organic matters that were still present before activation as shown in Figure 3a. The organic matters active in the raw soyabeans pod were decomposed during carbonization and the acid activation gave rise to pores development. It was indicated in the morphological arrangement of the disconnected amorphous like arrangement of the activated carbon obtainable in Figure $3 b$.

a.

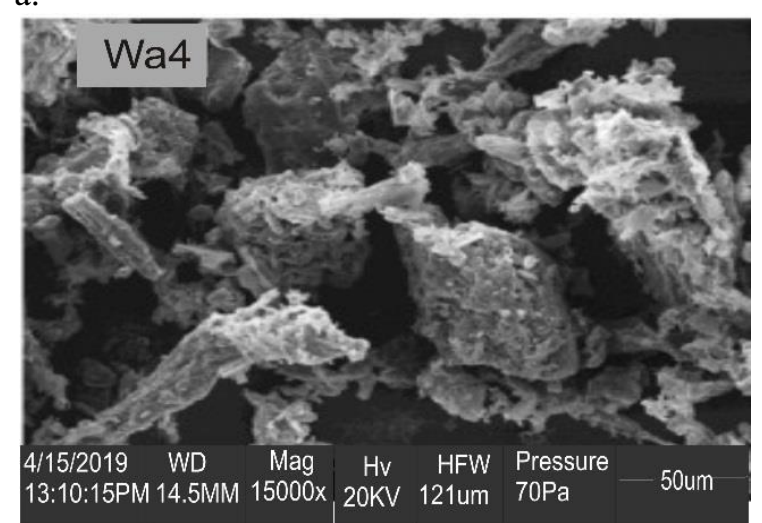

b.

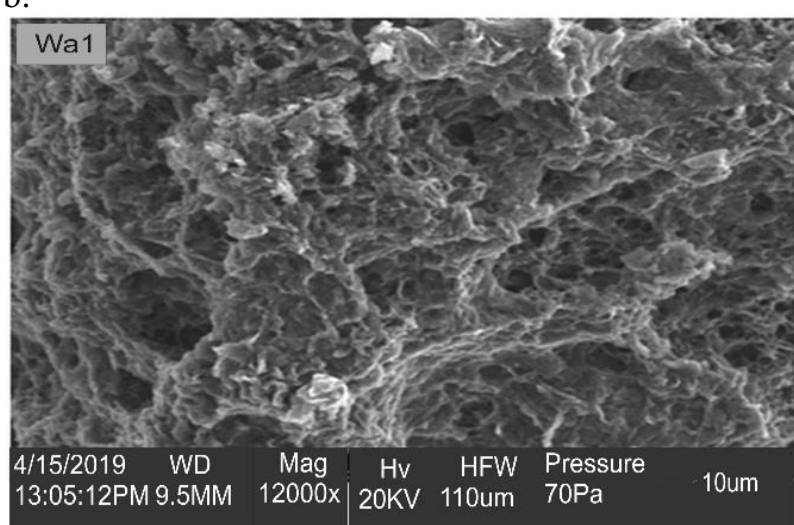

Figure 3. Morphological structure of (a) raw soyabeans pod (b) activated carbon prepared from soyabeans pod.

Figure 4 depicts the FTIR spectra for raw and activated carbon from soyabeans pod. The elongated bandwidth around 3417.98 and $3421.83 \mathrm{~cm}^{-1}$ evident in the raw and prepared activated carbon obtained from soyabeans pod was allotted to $\mathrm{O}-\mathrm{H}$ stretching. The concentrated band at about $2920 \mathrm{~cm}^{-1}$ is allotted to asymmetric $\mathrm{C}-\mathrm{H}$ stretching [21]. Aromatic rings or $\mathrm{C}=\mathrm{C}$ bonds account for the peaks at about 1614 as 
well as $1616 \mathrm{~cm}^{-1}$ in the raw-dried and activated carbon. $\mathrm{C}-\mathrm{H}$ asymmetric and symmetric bending, are associated with the bands at $1087 \mathrm{~cm}^{-1}$ meant for the raw in addition to the $1080 \mathrm{~cm}^{-1}$ for the activated carbon, in that order [22]. A substantial decrease was apparent for a succession of multifaceted bands varying between $1000-1384 \mathrm{~cm}^{-1}$ for the precursorafter acid activation, including alcohols, $\mathrm{C}-\mathrm{O}$ in carboxylic acids, esters as well as the $\mathrm{P}=\mathrm{O}$ bond in phosphate esters [23]. Certain feeble bands were also noticed together in the precursor and the activated carbon ranging from 400 to $700 \mathrm{~cm}^{-1}$ indicative of $\mathrm{C}-\mathrm{C}$ stretching. The presence and absence of certain bands in the activated carbon spectra is perhaps based on the carbonization and acid activation.

a.

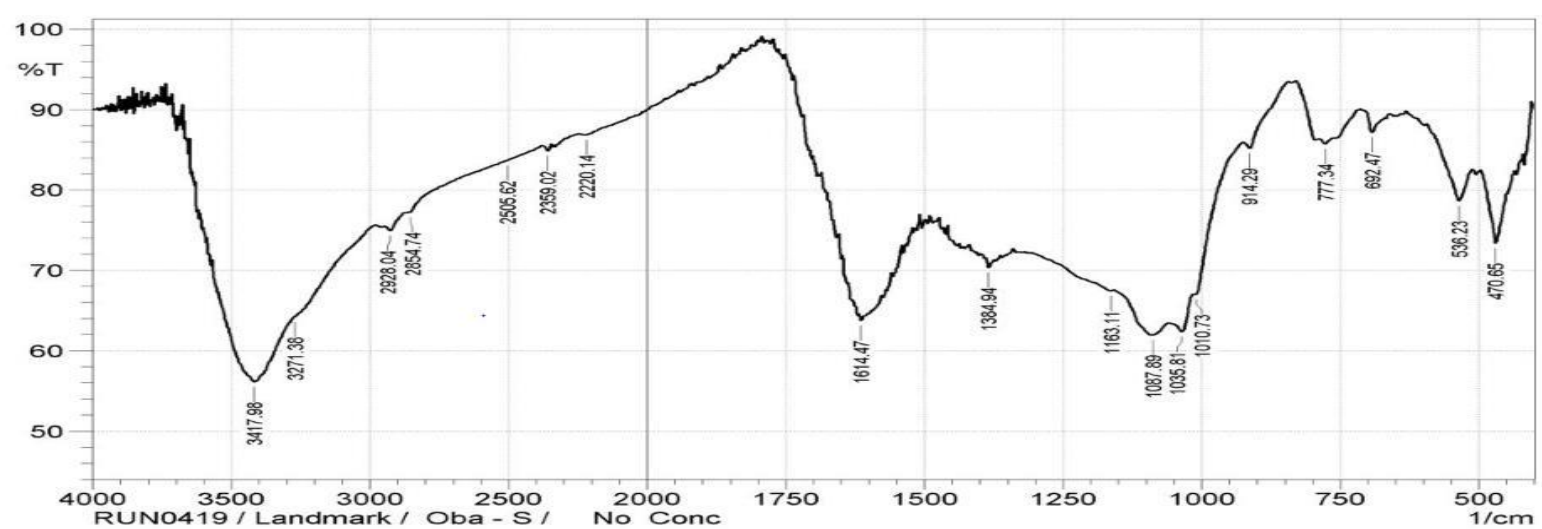

b.

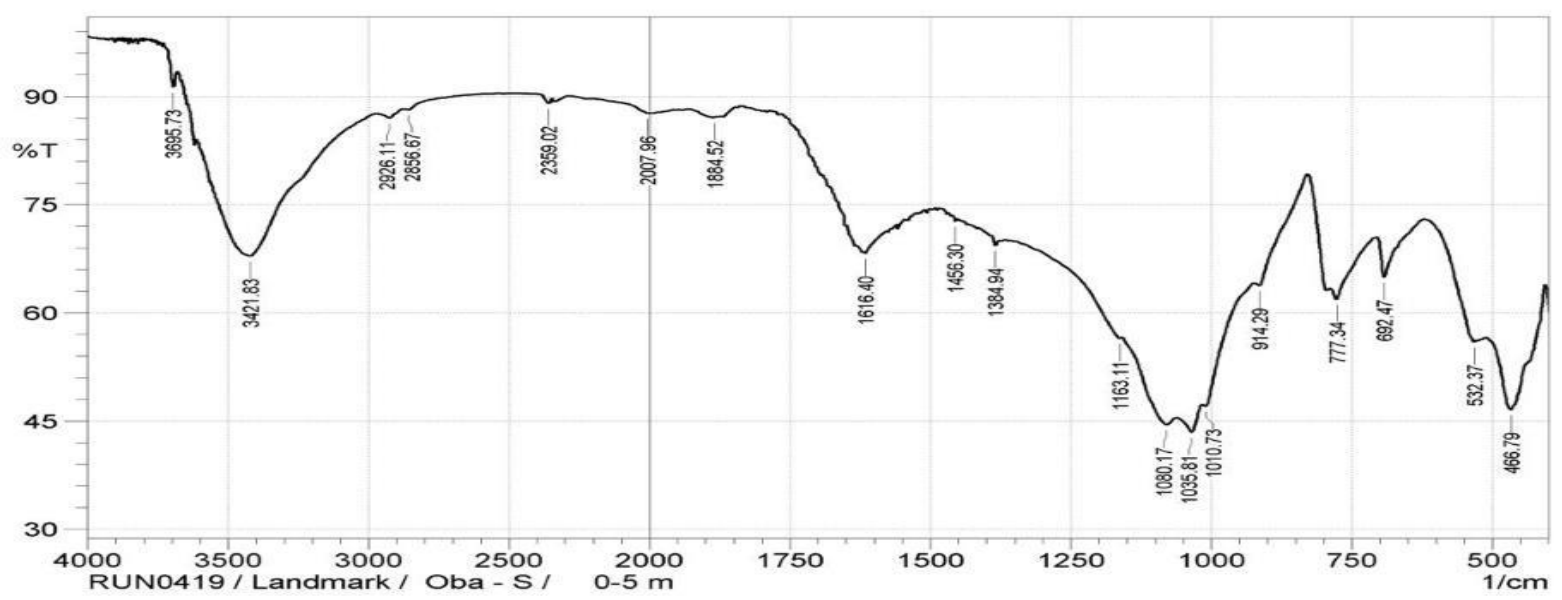

Figure 4. FTIR spectrum for (a) soyabeans pod (b) prepared activated carbon from soyabeans pod.

\section{Conclusions}

The development of high yield activated carbon from soyabeans pod was optimized at various conditions under study through a central composite design which is an aspect of the response surface methodology. This includes: impregnation ratio, activation time, and activation temperatures under study. The optimum restrictions attained include $1.06 \mathrm{M}, 305.34{ }^{\circ} \mathrm{C}$, and $89.95 \mathrm{~min}$ which translated to the yield of $36.02 \%$. It was discovered that acid activation and activation temperature from the three restrictions deliberated have the highest influence on the yield. The experimental design indicates that activated carbon from soyabeans pod can be chemically activated by means of phosphoric acid as activating agent as demonstrated. This is apparent from the BET, SEM and FTIR characterization analysis undertaken.

Conflicting interest: The Author's declared there is no conflicting interest. 


\section{References}

[1] Ekpete O A, Kpee F, Amadi J C and Rotimi R B 2010Adsorption of chromium (VI) and zinc (II) ions on the skin of orange peels (Citrus sinensis) Journal of Nepal Chemical Society26 31-39

[2] Ekpete O A, Horsfall Jr. M and Tarawou T 2011Adsorption of chlorophenol from aqueous solution on fluted and commercial activated carbon Journal of Nepal Chemical Society27 1-10

[3] Sugumaran P, Priya S V, Rauichandran P and Seshadri S 2012 Production and characterization of activated carbon from banana empty fruit bunch and delonixregia fruit pod Journal of Sustainable Energy and Environment31 125-32

[4] Santi R I and Zaki M 2014 The adsorption of $\mathrm{Pb}$ (II) ions on activated carbon from rice husk, irradiated by ultrasonic waves: kinetic and thermodynamics studies Journal of Natural Sciences Research, $\mathbf{4 2}$ $18-24$.

[5] El-Sayed G O, Yehia M M and Asaad A A 2014 Assessment of activated carbon prepared from corncob by chemical activation with phosphoric acid Water Resources and Industry78 66-75.

[6] Ekpete O A and HorsfallJrM2011 Preparation and characterization of activated carbon derived from fluted pumpkin stem waste (Telfairiaoccidentalis hook f) Research Journal of Chemical Sciences, $1310-7$

[7] Girgis B S, Yunis S S and Soliman A M 2002 Characteristics of activated carbon from peanut hulls in relation to conditions of preparation. Mater. Lett. 57 164-72

[8] Abechi S E, Gimba CE, Uzairu A and Dallatu YA, 2013 Preparation and characterization of activated carbon from Palm Kernel shell by chemical activation. Res. J. Chem. Sci. 3 54-61.

[9]Hirunpraditkoon S, Tunthong N, Ruangchai A and Nuithitiku K 2011 Adsorption capacities of activated carbons prepared from bamboo by $\mathrm{KOH}$ activation. World Acad. Sci. Eng. Technol6 20-24

[10] Gliscinska E and Babel K 2013 Preparation of activated carbon fibres from electrospun Poly acrylonitrile fibre mat and characterization of their chemical and structural properties. Fibres Text. East. Eur. 21 42-47

[11] Nowicki P, Kazmierczak J and Pietrzak R 2015 Comparison of physicochemical and sorption properties of activated carbons prepared by physical and chemical activation of cherry stones. Powder Technol. 269 312-319

[12] Liu B, Wang W, Wang N and Aub PCT2014 Preparation of activated carbon with high surface area for high-capacity methane storage. J. Energy. Chem. 23 662-8

[13] Rengaraj S, Seung-Hyeon M, and Sivabalm S 2002 Agricultural solid waste for the removal of organics: adsorption of phenol from water and wastewater by palm seed coat activated carbonWaste Management22 543-8

[14] Chaudhary N and Balomajumder C. 2014 Optimization study of adsorption parameters for removal of phenol on aluminum impregnated fly ash using response surface methodology Journal of the Taiwan Institute of Chemical Engineers, 453 852-9

[15] Tan I A W, Ahmad A L and Hameed B H 2008 "Preparation of activated carbon from coconut husk: optimization study on removal of 2,4,6-trichlorophenol using response surface methodology," Journal of Hazardous Materials 153 1-2 709-717

[16] Alam M Z, Ameem E S, Muyibi S A and Kabbashi N A 2009 The factors affecting the performance of activated carbon prepared from oil palm empty fruit bunches for adsorption of phenol Chemical Engineering Journal 155 1-2 191- 8

[17]Gottipati R and MishraS2012 Application of response surface methodology for optimization of Cr(III) and $\mathrm{Cr}(\mathrm{VI})$ adsorption on commercial activated carbons Research Journal of Chemical Sciences 2 $240-8$ 
[18] Nasehir-Khan E M Y, Faizal L M, Ismail A, Olugbenga S B and Mohd A A 2010 Effect of preparation conditions of activated carbon prepared from rice husk by $\mathrm{CO} 2$ activation for removal of $\mathrm{Cu}$ (II) from aqueous solution International Journal of Engineering and Technology 106

[19] Rusly S M and Ibrahim S 2010 Adsorption of textile reactive dye by palm shell activated carbon: response Surface Methodology World Academy of Science, Engineering and Technology 43892 5

[20] Kalavathy M H, Regupathi I, Pillai M G and Miranda L R, 2009 Modelling, analysis and optimization of adsorption parameters for H3PO4 activated rubber wood sawdust using response surface methodology (RSM) Colloids and Surfaces B: Biointerfaces 701 35-45

[21] Yagmur E., Ozmak M and Aktas Z 2008 A novel method for production of activated carbon from waste $t$ by chemical activation with microwave energy Fuel 87 3278-85

[22] Deng H, Li G, YangH, Tang J and Tang J 2010 Preparation of activated carbons from cotton stalk by microwave assisted $\mathrm{KOH}$ and $\mathrm{K}_{2} \mathrm{CO}_{3}$ activation Chemical Engineering Journal 163 373-81

[23] Deng H, Zhang G, Xu X, Tao G and Dai J 2010b Optimization of preparation of activated carbon from cotton stalk by microwave assisted phosphoric acid- chemical activation Journal of Hazardous Materials 182 217-24 